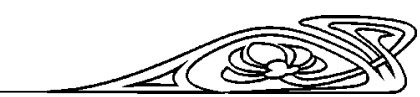

УДК 913(470.44)+002:001+577.4

\title{
СТРУКТУРА И ОСОБЕННОСТИ ФУНКЦИОНИРОВАНИЯ ГИС-НАЦИОНАЛЬНЫЙ ПАРК (На ПрИМЕРе «ГИС-национальный парк "Хвалынский"»)
}

\section{В.А. Данилов}

Саратовский государственный университет, кафедра геоморфологии и геоэкологии E-mail: kohavi@yandex.ru

В статье рассмотрена созданная автором специализированная геоинформационная система «ГИС-национальный парк "Хвалынский”». Показаны концептуальные основы ГИС, содержание отдельных модульных блоков, тематическая структура баз данных. Ключевые слова: национальный парк «Хвалынский», географические информационные системы, базы данных, тематические карты, охрана природы.

Structure and Features of Functioning "GIS-national park" (on an Example of "GIS-national Park "Hvalynsky"»)

\section{V.A. Danilov}

In article the specialised geoinformation system created by the author "GIS-national park "Hvalynsky"» is considered. Conceptual bases of the GIS, the maintenance of separate modular blocks, thematic structure of databases are shown.

Key words: national park "Hvalynsky», geographical information systems, databases, thematic cards, wildlife management.

Национальный парк «Хвалынский» был создан в 1994 г. на северо-востоке Саратовского Правобережья для сохранения ландшафтов лесостепной зоны европейской части России на самой южной границе их распространения. Территория парка характеризуется разнообразием и уникальностью ландшафтов [1]. Национальный парк с охранной зоной практически целиком занимает территорию Хвалынского муниципального района Саратовской области.

Основными задачами национального парка «Хвалынский», согласно [2], является как сохранение природных комплексов, уникальных и эталонных природных участков, историкокультурных объектов, так и создание условий для регулируемого туризма и отдыха в природных условиях. Выполнение таких весьма противоречивых задач невозможно без привлечения новых достижений науки и техники, в том числе и ГИС-технологий и данных дистанционного зондирования [3].

В статье рассмотрен опыт по созданию специализированной ГИС по управлению разнообразной деятельностью парка [1]. Данные исследования были ранее опубликованы в ряде работ [1, 4-6]. Особое внимание обращено на структуру и содержание баз данных, задействованных в разных модулях ГИС.

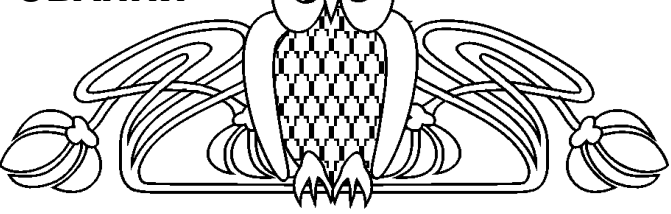

Процесс создания ГИС начался в 2002 году. Именно тогда были проведены первые комплексные ландшафтные исследования на территории парка и в охранной зоне [7]. Затем они были подкреплены полустационарными работами на полигонах-трансектах центрального участка парка, разносезонными маршрутными наблюдениями, снегогеохимическими и почвенногеохимическими исследованиями. Большое внимание было обращено на анализ опубликованных и фондовых материалов, обработку данных дистанционного зондирования, лесотаксационные материалы за разные годы. Накопленный массив информации и конкретные запросы дирекции парка позволили сформулировать концепцию и принципы создания будущей ГИС, структуру и содержание баз данных разных ее модулей.

Рассмотрим методологические и структурно-информационные особенности «ГИСнациональный парк “Хвалынский””.

Ими являются:

- использование в качестве основы крупномасштабной цифровой (топографической) карты с различным набором базовых слоев;

- организация и хранение баз данных согласно иерархической (древовидной) структуры;

- интеграция данных дистанционного зондирования Земли (ДЗ3) на различные периоды времени и с разным разрешением;

- взаимодействие с различными технологиями глобальных систем позиционирования (ГСП);

- представление материалов баз данных в разных формах и видах;

- принцип модульности структуры, каждый из которых выполняет строго определенные функции;

- создание и обновление банков данных мониторинговых и специализированных научных исследований;

- тематическое разнообразие картографических материалов, оцифрованных по имеющимся картам, и построенных на основе полевых исследований;

- наличие синтетических и аналитических карт, созданных на основе имеющихся данных с применением методов математического, картографического и других видов моделирования.

Использование ГИС-национальный парк ориентировано на разные категории пользователей, поэтому в ГИС реализован модульный принцип, с ориентацией содержания каждого модуля на определенную группу пользователей. 
В рассматриваемой ГИС модули «настроены» на посетителей и сотрудников парка (управленцевадминистраторов), научных работников.

В первом случае для посетителей-рекреантов модуль представлен в роли информационносправочной системы, содержащей информацию о территории и инфраструктуре парка, возможных видах рекреации и месте их расположения. Отличительными особенностями данного модуля являются широкое применение средств мультимедиа, представление информации в более наглядном и упрощенном виде, интеграция данных в сеть Интернет. Данный модуль имеет собственное имя - «Электронный гид».

Модуль администраторов-управленцев выполняет роль и справочной, и экспертной системы, обеспечивающей своевременную помощь в процессе принятия управленческих решений в рамках возложенных на национальный парк обязательств. Задача модуля состоит в предоставлении разнообразных аналитических и синтетических карт, полученных на основе обработки разной информации о территории парка. Отдельно выделяется подмодуль анализа лесотаксационных материалов за разные годы.

Отличительной особенностью административного модуля является интеграция баз данных ГИС, данных дистанционного зондирования Земли и глобальных систем позиционирования, позволяющая на местности в режиме реального времени уточнять информацию об объектах и явлениях на территории парка, определять их состояние и возможные изменения.

Наконец, «научный» модуль выполняет роль банка данных, аккумулирующего результаты специализированных исследований, с последующей их систематизацией, анализом и поиском зависимостей между отдельными природными компонентами. Данный модуль отличается большим количеством подмодулей, связанных со специализированными исследованиями: ландшафтными, геохимическими, гидрологическими, флористическими, зоологическими и др. В модуле широко используются различные методы геоинформационного моделирования - математического, картографического, экологического и др.

Базы данных являются информационной основой всей ГИС. Их состав и организация определяются перечнем входных и выходных данных, необходимых для решения функциональных задач национального парка.

Исходными материалами для формирования баз данных являются:

- топографические карты Хвалынского района и Саратовской области;

- тематические карты территории парка и охранной зоны;

- лесотаксационные материалы;

- данные полевых наблюдений/исследований;
- фондовые и опубликованные материалы различных организаций и ведомств;

- нормативные данные для специализированных расчетов.

\section{Картографическая база данных}

Основой картографической базы данных является открытая для пользования крупномасштабная цифровая векторная карта территории Хвалынского муниципального района масштаба 1 : 50 000, дополненная цифровой векторной картой масштаба 1 : 200000 Саратовской области. На отдельные участки парка созданы цифровые векторные карты открытого содержания масштаба 1 : 25 000, а на территорию учебно-научного стационара Саратовского государственного университете им. Н.Г. Чернышевского - в масштабе 1 : 500.

Цифровые топографические карты открытого содержания предназначены для пространственной координации и визуализации данных по природным и рекреационным условиям и ресурсам национального парка, комплексного изучения Хвалынского административного района и интеграции этих данных в геоинформационную систему «Особо охраняемые природные территории Саратовской области». Все цифровые векторные карты представлены в единой системе координат WGS-84, что позволяет совмещать их с различными тематическими слоями и данными дистанционного зондирования в формате GeoTIFF, без преобразования последних, с целью получения любых выходных карт.

Наличие цифровых карт с разной линейкой масштабов обеспечивает лучшую визуализацию и вывод данных с нужной степенью их генерализации и детализации. Цифровые картографические слои соответствуют геореляционной модели хранения данных и содержат атрибутивные таблицы, являющиеся компонентами пространственных баз данных. Совмещение пространственных и атрибутивных типов данных достигается использованием ключей и индексов, для связи с объектами отдельных тематических таблиц. Это позволяет обрабатывать запросы пользователей ГИС с одновременным привлечением картографических и атрибутивных данных, а также представлять результаты обработки запросов в виде карт, тематическая нагрузка которых определяется содержанием атрибутивных таблиц. Карты сопровождаются текстовыми описаниями, графикой и фотографиями.

Формирование пространственной (картографической) базы данных обеспечивается следующими процедурами:

- созданием базовых электронных карт открытого содержания в векторном формате на территорию Хвалынского национального парка, Хвалынского административного района и Саратовской области в указанных выше масштабах, на основе соответствующих топографических карт и космических снимков высокого разрешения и аэрофотоснимков; 
- карта лесов и водных объектов, редких и

- построением цифровой модели рельефа Хвалынского НП, других математикокартографических моделей, тематических электронных карт парка и охранной зоны для научного и управленческого модулей;

- созданием упрощенных справочно-информационных карт и организацией электронной фото- и видеотеки, отражающей содержание экспозиций музеев г. Хвалынска, с фотографиями основных и редких видов флоры и фауны, обнажений горных пород, форм рельефа, гидрологических объектов, памятников природы, истории и культуры и пр. на территории парка и его охранной зоны для ГИС-модуля «Электронный гид».

Картографическая база данных «ГИС НП “Хвалынский”» в настоящее время включает десятки цифровых карт различного содержания и масштабов, выполненных в векторном формате. Рассмотрим тематическую структуру картографической базы данных ГИС.

Общегеографические базовые карты:

- Саратовской области масштаба 1 : 200 000;

- Хвалынского муниципального района масштаба 1 : 50 000;

- центрального участка Хвалынского национального парка и его охранной зоны масштаба $1: 25000$;

- учебно-научного стационара СГУ масштаба $1: 500$.

Карты географического положения территориальных структур с границами.

- местоположение Саратовской области на территории России;

- административно-территориального деление Саратовской области и НП «Хвалынский» на ней;

- местоположение НП «Хвалынский» на ландшафтной карте России;

- местоположение НП «Хвалынский» в структуре ландшафтов Нижнего Поволжья и Саратовской области;

- карта границ функциональных зон НП «Хвалынский»;

- карта лесничеств бывшего Хвалынского лесхоза; делов.

- карты лесоустроительных кварталов и вы-

Тематические карты и математикокартографические модели картьл:

а) природно-ресурсные инвентаризационные

- карта рельефа Саратовской области;

- геологическая карта Хвалынского муниципального района с четвертичными отложениями и без них;

- геоморфологическая карта Хвалынского муниципального района;

- карта почв и почвообразующих пород Хвалынского муниципального района;

- геоботаническая карта Хвалынского муниципального района, включая ареалы реликтовых и эндемичных растений; исчезающих видов растений и животных на территории Хвалынского муниципального района;

- зоогеографическая карта НП «Хвалынский»;

- карта породного состава лесов Хвалынского муниципального района;

- ландшафтная карта Хвалынского муниципального района;

б) картыл морфометрии рельефа Хвальнского

- ярусов рельефа;

- экспозиции склонов;

- углов наклона земной поверхности;

- горизонтального расчленения;

- вертикального расчленения;

- водосборных бассейнов (порядков, площадей и др.);

- трехмерная GRID-модель территории;

в) констатирующие и оченочнье карты природных процессов и геоэкологических ситуаций на территорию Хвалынского мунищипального района:

- участков с активным развитием эрозионных процессов;

- участков потенциального развития эрозионных процессов;

- негативных процессов в почвенном покрове;

- группа ландшафтно-геохимических карт (концентрации химических веществ в почвах, водах, растительности, снеговом покрове по отношению к фоновому содержанию и ПДК) центральной части НП «Хвалынский»;

- толщины снегового покрова и запасов влаги в снеге в разных урочищах центральной части НП «Хвалынский» (по данным снегомерной съемки);

- толщины снегового покрова (по результатам моделирования);

- проблемных геоэкологических ареалов;

- устойчивости геоэкосистем к хозяйственному воздействию центральной части НП «Хвалынский»;

- оценочные лесотаксационные карты-схемы (просматриваемости, санитарно-гигиенического состояния, проходимости, ландшафтно-эстетической и рекреационной привлекательности, оценки бонитета лесных насаждений и др. по материалам лесотаксационных работ);

- карта рекреационной емкости геоэкосистем;

- модельных полигонов-трансект и точек комплексного ландшафтно-экологического описания на территории центральной части НП «Хвалынский»;

г) инвентаризационные и оченочные карты рекреации и отдыха:

- транспортной доступности различных ного района;

- экологических троп на территории НП «Хвалынский»; муниципального района: участков территории Хвалынского муниципаль- 
- визуальных бассейнов и панорамных площадок на территории центрального участка НП «Хвалынский»;

- живописности отдельных участков НП «Хвалынский»;

- археологических памятников на территории Хвалынского муниципального района;

д) Цифровая модель рельефа Хвальнского муниципального района.

Наряду с двухмерными картами, в ГИС представлены трехмерные данные, в частности цифровая GRID-модель рельефа (ЦМР) территории Хвалынского муниципального района с размером сети 50 х 50 м. Исходной ее основой стали отметки высот и изолинии топографической карты масштаба 1 : 50 000. Для более точного построения цифровой модели применялись линии, отражающие структуру поверхности рельефа, обрывы, промоины, тальвеги, линии и объекты гидрографической сети, уточненные по результатам дешифрирования космического снимка высокого разрешения. ЦМР может применяться в весьма разнообразных сферах деятельности: при вычислении различных морфометрических показателей рельефа, расчете визуальных бассейнов и панорамных точек, построении профилей поперечного сечения по производным линиям, оценке формы склонов через кривизну их поперечного и продольного сечения, интерполяции высот, генерации сети тальвегов и водоразделов, создании виртуально-реальностных моделей местности [8].

Созданная ЦМР территории Хвалынского муниципального района позволяет использовать ее для решения различных задач. Например, в туристско-рекреационных целях можно использовать ЦМР при построении и анализе профилей существующих и планируемых туристических троп, произвести их увязку с панорамными точками, точно определить длину и крутизну маршрута и др. ЦМР важна при оценке потенциальной опасности развития линейной и других форм эрозии, в зависимости от типа землепользования и ее интенсивности, для получения качественных и количественных характеристик морфометрических показателей рельефа и т.п. Данные задачи достаточно легко решаются с применением ЦМР и практически невыполнимы при использовании обычных цифровых карт. В настоящий момент более широко распространен радиолокационный способ получения и построения ЦМР, облегчающий скорость ее создания [9].

Данные дистанционного зондирования

В «ГИС-НП “Хвалынский”» добавлены данные дистанционного зондирования. Основной частью базы данных является фрагмент крупномасштабного космического снимка территории Хвалынского муниципального района, полученный с российского спутника «Ресурс-01» с помощью длиннофокусной камеры МКФ-1000 в августе 1999 года. Это панхроматический двухзональный фотографический снимок с разрешением в 4-5 м в центре кадра площадью 6400 км² $^{2}$ Фотокосмоснимок был отпечатан с негатива, сканирован и переведен в цифровую форму. Затем с помощью программы AutoCAD Мар и модуля RasterDesign была сделана геометрическая коррекция снимка по серии опорных точек и его территориальная привязка в системе координат WGS-84. Пространственное разрешение снимка соответствует примерно карте масштаба $1: 10$ 000-1:25000.

В систему также добавлен среднемасштабный мультиспектральный снимок октября 2007 г., полученный с помощью сенсоров MSS и ET американского спутника Landsat-5, со следующими каналами: синим, зеленым, красным, ближним инфракрасным, коротковолновым инфракрасным, инфракрасным и тепловым инфракрасным. Пространственное разрешение панхроматических каналов данного спутника составляет 30 м и примерно соответствует карте масштаба $1: 50$ 000-1: 100 000. Снимок изначально выполнен с геопривязкой в формате GeoTIFF, поэтому не требует территориальной привязки к системе координат WGS-84.

Снимки могут использоваться как самостоятельно, так и в качестве подложки цифровых векторных карт, обеспечивая более достоверное определение признаков объектов при выделении участков, занятых различными видами растительности и типами землепользования, выявление нарушенных и застроенных территорий, оценку плотности и формы эрозионной сети, выбор эталонных (модельных) участков [8].

Например, изучение цвета, структуры и текстуры различных комбинаций каналов мультиспектрального космического снимка позволило определить ареалы хвойных, мелколиственных и твердолиственных древесных пород, площадь и локализацию вырубок, сенокосов, травянистых участков, садовых плантаций и др. [10, 11].

Полевое дешифрирование содержания космических снимков выполнялось во время проведения летних ландшафтно-экологических работ. По его результатам была уточнена карта землепользования территории национального парка и его охранной зоны, определены участки активного развития различных форм эрозии и береговой абразии, уточнены местоположение и ареал произрастания коренных сосновых насаждений, участки потенциального расширения территории национального парка и др.

\section{Атрибутивная база данных}

В понятие атрибутивной (непространственной, не связанной с местоуказанием) базы данных (АБД) входят текстовые и табличные описания, опубликованные и фондовые материалы различного содержания, рассматривающие природу, историю и культуру Хвалынского Приволжья, содержащей информацию по обслуживанию туристов, экологической обстановке и состоянию геоэкосистем парка, научной, просветительской, 
природоохранной деятельности парка, экспозициям хвалынских музеев и пр.

Основу атрибутивной базы данных составляют лесотаксационные описания по Хвалынскому лесничеству, выполненные в 1994 году. Лесотаксационные материалы были переведены из аналоговой в цифровую табличную форму. После проведения процедуры геокодирования - поиска соответствия между табличными объектами и их пространственным представлением с помощью индексов, - стало возможно строить различные лесотаксационные карты-схемы на основе табличных данных.

Элементарной пространственной единицей (элементарным полигоном) в лесотаксационных документах является таксационный выдел. Таксационный выдел в ГИС содержит следующую информацию: номер лесоустроительного квартала, описание выдела, его площадь, категория земель, хозяйственная категория, проектируемые хозяйственные мероприятия, преобладающая древесная порода, тип леса, бонитет, тип лесорастительных условий, год и тип вырубки, данные о захламленности выдела, описание элементов леса. Для каждого яруса лесных насаждений даются следующие характеристики: коэффициент состава, древесная порода, средний возраст, высота, диаметр, полнота, характеристика лесных культур, описание повреждений насаждений, описание травянистой растительности, характеристика древесно-кустарниковых растений, информация о потерях древесины на выделе, рекреационная характеристика выдела, санитарное состояние, проходимость, просматриваемость, тип ландшафта, характеристика почвы, характеристика подроста, его количество, средний возраст, высота, коэффициент состава, характеристика подлеска, степень густоты, комплексная оценка выдела.

Структуры атрибутов цифровых слоев и таксационных баз данных разных лет идентичны. После окончания лесотаксационных исследований в 2010 г. планируется добавление их результатов в АБД. Это позволит в перспективе разработать методику учета и внесения изменений в первичную базу, анализировать изменения в лесном фонде в период между лесотаксационными мероприятиями, а также приступить к организации постоянного комплексного мониторинга лесного фонда на основе ведения непрерывного лесоустройства.

Большую долю в АБД «ГИС НП “Хвалынский”» составляют материалы полевых ландшафтных описаний модельных площадок и полигоновтрансект. Исходный материал из полевых бланков переведен в электронную форму, составлена база данных, содержащая характеристики доминантных, субдоминантных и эпизодических урочищ по модельным фациям. Ландшафтно-экологическая информация была упорядочена по тематическим слоям и привязана к базовой топографической карте Хвалынского района.
В АБД также хранятся результаты химического анализа почвенных и водных проб, материалы полустационарных микроклиматических наблюдений по полигонам-трансектам, а также разнообразная текстовая и статистическая информация по национальному парку «Хвалынский», фототека, включающая цифровые фотографии различных урочищ парка, отдельных компонентов и элементов ландшафта, объекты рекреационнотуристской инфраструктуры и инженерного обустройства.

Пополнение атрибутивной информации преследует цель систематически и в течение длительного времени проводить мониторинг динамики природных явлений и процессов в пределах парка и охранной зоны. Накапливаемый фактический материал должен отвечать требованиям достоверности, массовости (исключение могут составлять данные по редким и исчезающим видам), репрезентативности и преемственности.

Картографические и атрибутивные базы данных различных модулей «ГИС НП «Хвалынский»»» дополняются блоком моделирования.

Блок моделирования включает как готовые прикладные программы, так и встроенный в ГИС-пакеты язык программирования MapBasic или пакет MapX, позволяющие создавать свои собственные продукты для целей математикокартографического моделирования и решающие задачи буферизации, кластеризации, интеграции и других операций пространственного анализа. При этом базовая топографическая карта с набором тематических карт и баз данных является не просто подложкой, а полноценным источником по созданию новых разнообразных синтетических карт.

В рамках «ГИС НП “Хвалынский”» с помощью различных программ были определены зоны видимости/невидимости с разных точек, рассчитаны значения транспортной доступности и удаленности рекреационных угодий, оценена степень опасности эрозионных процессов, определены микроклиматические различия, рассчитана толщина снежного покрова по территории района, определены площади рассеивания в приземном воздухе различных загрязняющих веществ, проведена оценка уровня их концентрации и др.

Сам процесс создания «ГИС НП "Хвалынский”» включает несколько этапов:

1) этап разработки концепции и содержательной структуры ГИС по различным модулям: туристическому, административному и научному;

2) создания и постепенного наполнения картографических и атрибутивных баз данных для различных модулей ГИС;

3) разработки соответствующих модульных интерфейсов;

4) размещения, апробации и поддержки ГИС в дирекции парка, визит-центре, учебно-научном стационаре Саратовского госуниверситета, лабораториях и компьютерных классах географического факультета СГУ; 
5) интегрирования «ГИС НП “Хвалынский”» в «ГИС “Саратовская область”» и развертывания элементов ГИС в глобальной сети Интернет.

В настоящее время по отдельным структурным модулям выполняются работы на 3,4 и 5 этапах создания ГИС. Постоянно ведется пополнение картографических и атрибутивных баз данных по результатам полевых научных исследований.

Кратко охарактеризуем и рассмотрим вариант реализации информационно-справочного модуля «Электронный гид» «ГИС НП “Хвалынский”» на платформе программного пакета ГИС МарInfo 8.5 Professional [12], интегрированного в «ГИС “Особо охраняемые природные территории Саратовской области”».

ГИС-оболочка Mapinfo позволяет масштабировать картографическое изображение, компоновать тематические слои, сопровождать цифровую карту текстовым описанием, фотографиями и другими данными на основе гиперссылок. Администратор модуля в случае необходимости может редактировать базы данных, изменять свойства отображения целого слоя или объекта по отдельности, создавать и удалять новые объекты, изменять геометрические характеристики уже созданных объектов, атрибутивные данные.

Для пользователей модуля помимо возможности изменять отображаемые слои карты, реализованы следующие элементы интерфейса.

Средства навигаиии представлены следующими функциями: перемещение по карте; уменьшение и увеличение масштаба карты; отображение обзорного окна текущей карты; получение атрибутивной и другой информации об объектах; быстрый поиск населенного пункта; возможность получения растрового представления картографического материала.

Подсистема поиска позволяет выполнять поиск и отображение объекта на карте по полному названию или его части с указанием категории. В системе присутствуют следующие категории объектов, по которым осуществим поиск: топонимы, экологические тропы, историко-культурные и археологические памятники, места и объекты рекреации и отдыха (санатории, профилактории, гостиницы, кемпинги, кафе, бары, рестораны и др.), места оказания неотложной помощи. Отдельно выделена кнопка быстрого поиска по экологическим тропам (сложность и продолжительность их прохождения).

Дополнительные возможности: функция измерения линейных и площадных значений; отображение/скрытие условных обозначений по объектам, отображенным на карте; добавление и редактирование собственных меток и маршрутов на карте.

Остальные модули «ГИС НП “Хвалынский”» основаны на том же интерфейсе. Они отличаются от рекреационного модуля и большим тематическим набором банков данных, наличием подмодулей, представленных кнопками быстрого вызова и отвечающих за определенные функции, большой степенью свободы при работе с картой, возможностью подключения и использования прикладных программ моделирования.

Как известно, задача географии - познать типичное в индивидуальном и выявить индивидуальное в типичном. Национальный парк «Хвалынский» является типичным представителем лесостепного Приволжья, но в то же время уникальным уголком Европейской России. Как видится, «ГИС НП “Хвалынский”» может стать ядром научной, рекреационно-туристской и образовательно-воспитательной работы не только в пределах парка, но и в рамках единого природно-историко-культурного и рекреационнотуристского комплекса «Хвалынский национальный парк - малый исторический город Хвалынск».

\section{Библиографический список}

1. Макаров В.3., Чумаченко А.Н., Савинов В.А., Данилов B.A. Национальный парк «Хвалынский»: ландшафтная характеристика и географическая информационная система / Под ред. В.З.Макарова. Саратов, 2006. 148 с.

2. Положение о федеральном государственном учреждении «Национальный Парк “Хвалынский”». Приказ МПР России № 521 от 6 июня 2003 г. URL: http://base.consultant. $\mathrm{ru} /$ cons/cgi/online.cgi?req=doc;base=EXP;n=469326 (дата обращения: 14.04.2010).

3. Дити Л.Ю., Равкин Ю.С., Алсынбаев К.С. Экспертноаналитическая географическая информационная система (ГИС) «Пространственно-временная динамика экосистем Урала и Сибири» // Биоразнообразие и динамика экосистем: информационные технологии и моделирование. Новосибирск, 2008. С. 207-257.

4. Макаров В.З., Данилов В.А. Волжская «Швейцария»Хвалынский национальный парк: природные особенности и проблемы развития // Развитие физической географии и ландшафтной экологии в Саратовском университете: Сб. науч. тр. / Под ред. д-ра геогр. наук, проф. В.З. Макарова. Саратов, 2005. С. 85-93.

5. Макаров В.3., Чумаченко А.Н., Данилов В.А. и др. Некоторые результаты ландшафтно-экологических исследований на территории Хвалынского национального парка // Изв. Сарат. ун-та. Новая серия. 2007. Т. 7. Сер. Науки о Земле, вып. 1. С. 11-16.

6. Макаров В.3., Чумаченко А.Н., Данилов В.А. и др. Особо охраняемые природные территории Саратовской области: национальный парк, природные микрозаповедники, памятники природы, дендрарий, ботанический сад, особо охраняемые геологические объекты/ Комитет охраны окружающей среды и природопользования Саратовской области; Науч. ред. В.3. Макаров. Саратов, 2007. $300 \mathrm{c}$.

7. Макаров В.3., Чумаченко А.Н., Федоров А.В. и др. Ландшафтно-экологические исследования в Хвалынском национальном парке (программа и результаты) // Безопасность и устойчивое развитие Нижнего Поволжья: Материалы III Региональной науч.-практ. конф., г. Волжский, 28 ноября 2003 г. Волгоград, 2003. C. $124-126$. 
8. Капралов Е.Г., Кочкарев А.В., Тикунов В.С. Геоинформатика: Учебник для студ. вузов / Под ред. В.С. Тикунова. М., 2005. $480 \mathrm{c}$.

9. Павлова А.Н. Геоинформационное моделирование речного бассейна по данным спутниковой съемки SRTM (на примере бассейна р. Терешка) // Изв. Сарат. ун-та. Новая серия. 2009. Т. 9. Сер. Науки о Земле, вып. 1. С. 39-44.

10. Книжников Ю.Ф., Кравцова В.И., Тутубалина О.В. Аэрокосмические методы географических исследований. M., 2004. $336 \mathrm{c}$.
11. Жилеев М.Ю. Обзор применения мультиспектральных данных ДЗ3 и их комбинаций при цифровой обработке // Геоматика. 2009. № 3. С. 56-64.

12. Данилов В.А. Информационно-справочная ГИС НП Хвалынский // Всероссийская молодежная выставкаконкурс прикладных исследований, изобретений и инноваций. 27- 28 октября 2009 г.: Сб. материалов. Саратов, 2009. С. 139. 